\title{
Outcomes of Early-onset Preeclampsia With Severe Features at the University Hospital in Southern Thailand: a 15-year Experience
}

\section{Noppasin Khwankaew}

Prince of Songkla University

Rapphon Sawaddisan ( $\square$ sai.sawaddisan@gmail.com )

Prince of Songkla University https://orcid.org/0000-0003-1588-8789

Chitkasaem Suwanrath

Prince of Songkla University https://orcid.org/0000-0001-8634-2359

\section{Alan Geater}

Faculty of Medicine, Prince of Songkla University https://orcid.org/0000-0003-1219-9814

\section{Research Article}

Keywords: Preeclampsia, maternal outcomes, neonatal outcomes, predictive factors

Posted Date: February 10th, 2021

DOI: https://doi.org/10.21203/rs.3.rs-182687/v1

License: (c) (i) This work is licensed under a Creative Commons Attribution 4.0 International License. Read Full License 


\section{Abstract}

Purpose: To evaluate outcomes and factors associated with adverse outcomes among patients with early-onset preeclampsia with severe features at Songklanagarind Hospital.

Methods: A retrospective study of 326 singleton women with early-onset preeclampsia with severe features treated at Songklanagarind Hospital between 2004-2019 was conducted. Baseline characteristics, management and outcomes were reviewed. Multivariate logistic regression was used to evaluate predictors of adverse outcomes. Statistical significance was set at $p<0.05$.

Results: There were no maternal mortalities, with $3.1 \%$ stillbirths and $6.7 \%$ neonatal deaths. High maternal serum creatinine (OR $3.26,95 \% \mathrm{Cl} 1.27-8.36, p=0.01)$ was significantly associated with adverse maternal outcomes. Early gestational age at delivery [ 28 weeks (OR 16.63, 95\% Cl 6.95-39.80, p <0.01), 28-32 weeks (OR 3.24, 95\% Cl 1.54-6.85, p <0.01)], maternal diabetes mellitus (OR 5.62, 95\% Cl 1.4322.06, $p=0.01)$, high maternal serum creatinine (OR 2.66, 95\% Cl 1.20-5.93, $p=0.02$ ) and elevated serum aminotransferases $(\mathrm{OR} 2.26,95 \% \mathrm{Cl} 1.19-4.29, \mathrm{p}=0.01)$ were associated with serious adverse perinatal outcomes.

Conclusions: Early-onset preeclampsia with severe features had favorable outcomes. Maternal diabetes mellitus, high serum creatinine, elevated serum aminotransferases and early gestational age at delivery were factors associated with poor outcomes.

\section{Introduction}

Preeclampsia is a pregnancy-specific multiple-organ disorder associated with high rates of maternal and neonatal morbidity and mortality. Recent studies reported incidence ranges from $2.7-8.2 \%$ globally and $2.2 \%$ in Thailand [1, 2]. Appropriate diagnosis and timely management are crucial as more than half of these morbidities and mortalities are preventable [3].

The diagnosis of preeclampsia is made by recognizing new onset hypertension plus proteinuria and/or other signs and symptoms of organ dysfunction during pregnancy [4]. Preeclampsia is classified into early- and late-onset, defined as those requiring delivery before or after 34 weeks of gestation [5]. The pathophysiology of early-onset preeclampsia is abnormal placental development leading to deficient uterine spiral artery remodeling, while late-onset preeclampsia mainly arises from degenerative placenta accompanied by maternal predisposition to cardiovascular or metabolic disease. Both types of preeclampsia lead to dysfunctional maternal peripheral endothelial cells and systemic inflammatory responses, which lead to organ dysfunction and death in some women [6-9]. The fetuses are also affected from utero-placental insufficiencies. They have higher risk of growth restriction, hypoxia and death $[8,9]$.

Since the cause of preeclampsia is principally from the placenta, termination of pregnancy is the definitive treatment for the affected women. However, when preeclampsia is diagnosed early in gestation, 
physicians have to take into account the high neonatal mortality and morbidity related to preterm birth. [10] Attempts to prolong pregnancy at risk of preeclampsia using expectant management practices may improve neonatal outcomes. On the other hand, pregnancy prolongation may increase morbidity and mortality in some women $[4,11]$.

Songklanagarind Hospital is the university hospital and tertiary care center in Southern Thailand, and thus receives a large number of referral preeclampsia women from all of the southern provinces. In 2018, the incidence of preeclampsia with severe features in our hospital was $4.2 \%$ of the total births (140/3299), of which about 11\% (15/140) were early-onset. Early-onset preeclampsia with severe features is a condition which needs suitable guidelines, meticulous evaluation, and good physician judgment. To date, there have been no studies evaluating maternal and neonatal outcomes among cases of early-onset preeclampsia with severe features in Southern Thailand. Therefore, we aimed to evaluate maternal and neonatal outcomes among women with early-onset preeclampsia with severe features and also possible predictive factors for poor maternal and neonatal outcomes.

\section{Material And Methods}

A retrospective analytical study was conducted after approval by the Institutional Review Board of the Faculty of Medicine, Prince of Songkla University (REC 63-126-12-4). The medical records of women who delivered at Songklanagarind Hospital during a 15-year study period (November 1, 2004 to October 31, 2019) were reviewed. The inclusion criteria were: 1) singleton pregnant woman; and 2) early-onset preeclampsia with severe features according to the diagnostic criteria used in the period of diagnosis.

The exclusion criteria were women with severe medical problems including heart disease, severe anemia $(\mathrm{Hb}<7 \mathrm{mg} / \mathrm{dl})$, cirrhosis, thrombocytopenia diagnosed prior preeclampsia, severe systemic infection, and serious antepartum complications, including placenta previa, placenta accreta spectrum disorder, intraamniotic infection and having fetal anomalies.

The diagnosis and management clinical practice guidelines of Songklanagarind Hospital were according to the American College of Obstetricians and Gynecologists (ACOG) guidelines. The 15-year period of data collection included two ACOG diagnostic guidelines, the 2002 version and the 2013 versions $[4,12]$.

Sample size was calculated based on the prevalence of adverse maternal outcomes with proportion $(p)=$ 0.105 (retrieved from a pilot study of Songklanagarind Hospital between 2018 and 2019), alpha = 0.05, and error $(d)=0.05$; at least 145 cases were needed.

Demographic characteristics, treatment details until delivery along with maternal and neonatal outcomes were retrieved from the Medical Statistics Unit of the Department of Obstetrics and Gynecology and the Hospital Information System of Songklanagarind Hospital.

Women were identified as having adverse outcomes if they had at least one of the following: 1) death;2) abruptio placentae; 3 ) pulmonary edema; 4 ) posterior reversible encephalopathy syndrome (PRES); and 
5) postpartum hemorrhage. Serious adverse perinatal outcome was defined as at least one of the following; 1) stillbirth; 2) neonatal death; and 3) low 5-minutes Apgar score (<7).

Data were recorded using EpiData Version 3.1. Statistical analysis was done using Stata 14.2.

Mean (SD), median (IQR) or number (\%) were used as appropriate regarding the type of variables and data distribution. Multivariate logistic regression was used to estimate odds ratios for the association between variables and adverse maternal and perinatal outcomes. Statistical significance was set at $p<$ 0.05 .

\section{Results}

There were a total of 41,884 singleton deliveries during the 15-year period (from November 1, 2004 to October 31, 2019) at Songklanagarind Hospital, of whom 2087 were diagnosed with preeclampsia and 392 women were diagnosed with early-onset preeclampsia with severe features. Sixty-six women were excluded ( 23 due to severe medical problems and 43 due to serious antepartum complications). Finally, 326 early-onset preeclampsia with severe features women were analyzed. (Fig. 1)

The demographic data are shown in Table 1. Most of the diagnoses were based on elevated blood pressure defined as systolic blood pressure $\geq 160 \mathrm{~mm} \mathrm{Hg}$ and/or diastolic blood pressure $\geq 110 \mathrm{~mm} \mathrm{Hg}$ (314/326 women, $96.3 \%$ ) and significant proteinuria defined as urine protein $\geq 300 \mathrm{mg} / 24$ hours or spot urine protein to creatinine ratio $\geq 0.3$ or urine protein dipstick $\geq 2+(301 / 326$ women, $92.3 \%)$, with $178 / 326$ women $(54.6 \%)$ reporting the symptoms of headache, blurred vision or epigastrium pain. The pre-delivery management followed the ACOG recommendations $[4,14]$ in nearly all cases. Only 5/326 $(1.5 \%)$ women did not receive magnesium sulfate for maternal neurostabilization. 
Table 1

Demographic data $(\mathrm{N}=326)$

\section{Characteristics}

Maternal age (years)

Advanced maternal age ( $\geq 35$ years)

Nulliparity

Gestational age at diagnosis (weeks)

Body mass index $\left(\mathrm{kg} / \mathrm{m}^{2}\right)$

Obesity (body mass index $\geq 30 \mathrm{~kg} / \mathrm{m}^{2}$ )

Obstetric complications

Previous pregnancy-induced hypertension

Gestational hypertension

Preeclampsia without severe features

Preeclampsia with severe features

History of indicated preterm delivery from pregnancy-induced hypertension

Medical diseases

Chronic hypertension

Renal disease

Diabetes mellitus

Systemic lupus erythematosus

Thyroid disease

ASA usage

Gestational age at start (weeks)

Duration of ASA usage (weeks)
$\mathbf{N}(\%)$ or Median (IQR)

$32(28,36)$

$109(33.4)$

127 (39.0)

$31.1(28.6,32.7)$

$23.3(20.9,27.0)$

50 (14.7)

58 (17.8)

4 (6.9)

9 (15.5)

46 (79.3)

44 (13.5)
85 (26.1)

11 (3.4)

10 (3.1)

10 (3.1)

5 (1.5)

22 (6.7)

$14.5(12,17)$

$14(11,16)$

Most deliveries were induced (301/326, 92\%), with uncontrolled blood pressure being the most frequent indication. Cesarean section was performed in the majority of cases. Hydralazine was the most frequently used anti-hypertensive drug followed by nifedipine and labetalol. Nicardipine was used only in women whose blood pressure failed to be controlled by the above-mentioned drugs. Expectant management was offered in less than half of the women, with time from diagnosis to delivery ranging from 2 hours to 29 days. (Table 2 ) 
Table 2

Management of early-onset preeclampsia with severe features $(\mathrm{N}=$ 326)

\begin{tabular}{|ll|}
\hline Management & N (\%) or Median (IQR) \\
\hline MgSO4 & $321(98.5)$ \\
\hline Antihypertensive drugs & $271(83.1)$ \\
\hline Hydralazine & $224(82.7)$ \\
\hline Nifedipine & $38(14.0)$ \\
\hline Labetalol & $31(11.4)$ \\
\hline Nicardipine & $21(7.7)$ \\
\hline Expectant management & $141(43.3)$ \\
\hline Duration from diagnosis to delivery (hours) & $43(21,72)$ \\
\hline Types of preterm delivery & \\
\hline Spontaneous preterm labor & $26(8.0)$ \\
\hline Indicated preterm labor & $300(92.0)$ \\
\hline Uncontrolled blood pressure & $186(62.0)$ \\
\hline Persistent symptoms & $163(54.3)$ \\
\hline HELLP syndrome & $93(31.0)$ \\
\hline Fetal distress & $81(27.0)$ \\
\hline Renal dysfunction & $25(8.3)$ \\
\hline Pulmonary edema & $13(4.3)$ \\
\hline Abruptio placentae & $5(1.5)$ \\
\hline Eclampsia & $2(0.6)$ \\
\hline Route of delivery & $43(13.2)$ \\
\hline Vaginal delivery & $283(86.8)$ \\
\hline Cesarean section & \\
\hline
\end{tabular}

The maternal and neonatal outcomes are shown in Table 3. There was no maternal death. High percentages of uncontrolled blood pressure and persistent symptoms were observed. HELLP syndrome was noted in approximately one-third of cases. There were no eclamptic women during expectancy. Rates of other complications including pulmonary edema, abruptio placentae, postpartum hemorrhage and 
posterior reversible encephalopathy syndrome (PRES) were low. Three out of five women with abruptio placentae were detected during expectant management (within 48 hours after diagnosis), with the first sign being non-reassuring fetal heart rate; and two out of three had difficulties in blood pressure control. The other two women with abruptio placentae were detected at the time of diagnosis and received immediate termination of pregnancy. Regarding nine cases of postpartum hemorrhage, all had successful conservative management. 
Table 3

Maternal and perinatal outcomes $(\mathrm{N}=326)$

\section{Outcomes}

\section{Maternal outcomes}

Uncontrolled hypertension

Persistent symptoms

HELLP syndrome

Hemolysis

Elevated serum aminotransferases

Low platelet

Pulmonary edema

Abruptio placentae

Postpartum hemorrhage

Intracranial hemorrhage/ posterior reversible encephalopathy syndrome (PRES)

\section{Perinatal outcomes}

Birth weight

Apgar scores

Apgar score at $1 \mathrm{~min}$

Apgar score at $5 \mathrm{~min}$

Low 5-minutes Apgar score

Stillbirth

Neonatal death

Neonatal intensive care unit admission

Respiratory distress syndrome

Necrotizing enterocolitis

Bronchopulmonary dysplasia

Septicemia

Intraventricular hemorrhage

Convulsions
$1285(965,1645)$

$7(5,8)$

$N(\%)$ or Median (IQR)

$186(61.8)$

$228(70.0)$

$91(27.9)$

$6(1.8)$

76 (23.3)

45 (13.9)

$13(4.0)$

5 (1.5)

9 (2.8)

3 (0.9)

1285 (965,1645)

$9(7,9)$

66 (20.3)

10 (3.1)

22 (6.7)

289 (88.7)

87 (26.7)

59 (18.1)

40 (12.3)

33 (10.1)

7 (2.1)

$3(0.9)$ 
Regarding perinatal outcomes, about $90 \%$ of cases were alive with high rate of neonatal intensive care unit admission. Other complications were related to preterm delivery.

Univariate analysis showed that high maternal serum creatinine $(>1.1 \mathrm{mg} / \mathrm{dL})$ was the only factor associated with adverse maternal outcomes (OR 3.26, 95\% $\mathrm{Cl} 1.27-8.36, \mathrm{p}=0.01$ ). Multivariate analysis showed that early delivery at gestational age $(G A)<32$ weeks, maternal diabetes mellitus, high maternal serum creatinine and elevated serum aminotransferases (AST or ALT > $70 \mathrm{IU} / \mathrm{L}$ ) were risk factors for serious adverse perinatal outcomes adjusted by gestational age at diagnosis and maternal low platelet count. (Table 4)

Table 4

Multivariate analysis of factors associated with serious adverse perinatal outcomes ${ }^{\mathrm{a}}$

\begin{tabular}{|lll|}
\hline Maternal characteristic & $\begin{array}{l}\text { Serious adverse perinatal } \\
\text { outcomes } \\
\text { aOR }(95 \% \text { Cl) }\end{array}$ & $\begin{array}{c}\text { P- } \\
\text { value }\end{array}$ \\
\hline Gestational age at diagnosis & $13.13(0.14-68.17)$ & 0.47 \\
\hline GA $<28$ weeks & $1.10(0.14-8.54)$ & 0.93 \\
\hline GA 28-32 weeks & & \\
\hline GA 32-34 weeks & $16.63(6.95-39.80)$ & $<0.01$ \\
\hline Gestational age at delivery & $3.24(1.54-6.85)$ & $<0.01$ \\
\hline GA $<28$ weeks & & 0.01 \\
\hline GA 28-32 weeks & $5.62(1.43-22.06)$ & 0.02 \\
\hline GA 32-34 weeks & $2.66(1.20-5.93)$ & 0.01 \\
\hline Diabetes mellitus & $2.26(1.19-4.29)$ & 0.17 \\
\hline Serum Creatinine $>1.1 \mathrm{mg} / \mathrm{dL}$ & $1.83(0.78-4.31)$ & \\
\hline Elevated serum aminotransferases (AST or ALT $>70$ & & \\
\hline IU/L) & & \\
\hline Low platelet count $(<100000$ cells/dL) & & \\
\hline
\end{tabular}

${ }^{a}$ stillbirth, low 5-minutes Apgar score and neonatal death

\section{Discussion}


In this study, women with early-onset preeclampsia with severe features had favorable outcomes. High maternal serum creatinine was associated with adverse maternal outcomes, while delivery before 32 weeks of gestation, maternal diabetes mellitus, high serum creatinine and elevated serum aminotransferases increased the risk of adverse perinatal outcomes.

Similar to other studies, there was very low rate of maternal death among women with early-onset preeclampsia with severe features [13-18]. The incidence of HELLP syndrome was similar to that in a previous report in Thailand, about 28\% [13], but was more than those reported in other countries, which ranged from 12-15\% [14-17], which might be explained by the differences in gene expression in placenta, concentrations of anti-angiogenic factors or degrees of inflammatory responses in different ethnicities [19]. The rates of abruptio placentae and eclampsia reported in our study were low. Since two out of three women with abruptio placentae during expectant management had uncontrolled blood pressure, and all had non-reassuring fetal heart monitoring, we suggest that physicians should emphasize on blood pressure control and close observation of fetal health status. Poorly controlled blood pressure needs expedited delivery. In regard to perinatal outcomes, the perinatal mortalities were not different among various parts of the world [13-17].

We found that high maternal serum creatinine was the only factor associated with adverse maternal outcomes. It is understandable as kidney is one of the most frequently affected organs from inflammatory response and/or vasoconstriction in preeclampsia [6,20]. Once kidney dysfunction is evident, it indicates that other organs might be deteriorated. It is generally accepted that preterm delivery and maternal diabetes mellitus are related to adverse neonatal outcomes [10,21]. They were also associated with poor perinatal outcomes in our study. Apart from gestational age at delivery and maternal diabetes mellitus, we found that high maternal serum creatinine and elevated serum aminotransferases, which reflect the severity of preeclampsia, were also associated with serious adverse neonatal outcomes. Ganzevoort et al. reported that early gestational age at admission was the only significant factor influencing adverse neonatal outcomes. However, they did not evaluate the associations between maternal diabetes mellitus or maternal serum creatinine level and adverse outcomes [22].

The strengths of this study were; 1) large sample size; 2) complete and reliable database; 3) diagnoses and managements adherent to ACOG guidelines; and 4) determination of factors associated with adverse maternal and perinatal outcomes.

The limitation of our study was that it was a retrospective study. There were a few incomplete data such as laboratory results from referring hospitals, and patient histories and physical examination findings depended on the level of completion of medical records at the time of diagnosis. As aspirin prescription was just recently added to the preeclampsia prevention guideline in 2016 [23], there was only a small percentage $(6.7 \%)$ of aspirin prescription in our data. Because of this small percentage, the effects of aspirin prescription on the severity of preeclampsia might not be apparent. 
According to the favorable outcomes of the management of early-onset preeclampsia with severe features in our study, we encourage the use of the ACOG practice guideline. In addition, knowing factors associated with adverse maternal and perinatal outcomes can guide physicians in patient counselling and providing optimal neonatal care planning.

\section{Conclusion}

Women with early-onset preeclampsia with severe features had favorable outcomes. High maternal serum creatinine was associated with adverse maternal outcomes, while early gestational age at delivery, maternal diabetes, high serum creatinine and elevated serum aminotransferases increased the risk of adverse perinatal outcomes.

\section{Declarations}

\section{Declarations of Conflicts of Interest}

None

\section{Author contributions}

N Khwankaew: Protocol development, data collection or management, data analysis and manuscript writing/editing

R Sawaddisan: Protocol development, data collection or management, data analysis and manuscript writing/editing

C Suwanrath: Protocol development, data analysis and manuscript writing/editing

A Geater: Data analysis and manuscript writing/editing

\section{Acknowledgements}

The authors wish to thank Ms. Walailuk Jitpiboon of the Epidemiology Unit, Faculty of Medicine, Prince of Songkla University for her valuable advice and assistance in data analysis. No funding was required in conducting this study.

\section{References}

1. Abalos E, Cuesta C, Grosso AL, Chou D, Say L (2013) Global and regional estimates of preeclampsia and eclampsia: A systematic review. Eur J Obstet Gynecol Reprod Biol [Internet] 170:1-7. http://dx.doi.org/10.1016/j.ejogrb.2013.05.005

2. Abalos E, Cuesta C, Carroli G, Qureshi Z, Widmer M, Vogel JP, Souza JP (2014) Pre-eclampsia, eclampsia and adverse maternal and perinatal outcomes: a secondary analysis of the World Health 
Organization Multicountry Survey on Maternal and Newborn Health. BJOG 121: Supp1:14-24.

3. Berg CJ, Harper MA, Atkinson SM, Bell EA, Brown HL, Hage ML, Mitra AG, Moise KJ Jr, Callaghan WM (2005) Preventability of Pregnancy-Related Deaths. Obstet Gynecol 106:1228-1234.

4. American College of Obstetricians, Task Force on Hypertension in Pregnancy (2013) Hypertension in pregnancy. Report of the American College of Obstetricians and Gynecologists' Task Force on Hypertension in Pregnancy. Obstet Gynecol 122:1122-1131.

5. Wójtowicz A, Zembala-Szczerba M, Babczyk D, Kołodziejczyk-Pietruszka M, Lewaczyńska O, Huras H (2019) Early-and Late-Onset Preeclampsia: A Comprehensive Cohort Study of Laboratory and Clinical Findings according to the New ISHHP Criteria. Int J Hypertens 2019.

6. Burton GJ, Redman CW, Roberts JM, Moffett A (2019) Pre-eclampsia: pathophysiology and clinical implications. BMJ 366:1-15.

7. Triche EW, Uzun A, DeWan AT, Kurihara I, Liu J, Occhiogrosso R, Shen B, Parker J, Padbury JF (2014) Bioinformatic approach to the genetics of preeclampsia. Obstet Gynecol 123:1155-1161.

8. Sibai BM, Barton JR (2007) Expectant management of severe preeclampsia remote from term: patient selection, treatment, and delivery indications.Am J Obstet Gynecol 196:514.e1-9. doi:10.1016/j.ajog.2007.02.021.

9. Mol BWJ, Roberts CT, Thangaratinam S, Magee LA, De Groot CJM, Hofmeyr GJ (2016) Preeclampsia. Lancet 387:999-1011.

10. Saigal S, Doyle LW (2008) An overview of mortality and sequelae of preterm birth from infancy to adulthood. Lancet 371:261-269.

11. Sibai BM (2011) Evaluation and management of severe preeclampsia before 34 weeks'gestation. Am J Obstet Gynecol 205:191-8.

12. ACOG Committee on Obstetric Practice (2002) ACOG practice bulletin. Diagnosis and management of preeclampsia and eclampsia. Number 33, January 2002. American College of Obstetricians and Gynecologists.Int J Gynaecol Obstet 77:67-75.

13. Jantasing S, Tanawattanacharoen S (2008) Perinatal outcomes in severe preeclamptic women between 24-33(+6) weeks' gestation. J Med Assoc Thai 91:25-30.

14. McKinney D, Boyd H, Langager A, Oswald M, Pfister A, Warshak CR (2016) The impact of fetal growth restriction on latency in the setting of expectant management of preeclampsia. Am J Obstet Gynecol 214:395.e1-7.

15. Churchill D, Duley L, Thornton JG, Moussa M, Ali HSM, Walker KF (2018) Interventionist versus expectant care for severe pre-eclampsia between 24 and 34 weeks'gestation. Cochrane Database Syst Rev 2018.

16. Pettit F, Mangos G, Davis G, Henry A, Brown MA (2015) Pre-eclampsia causes adverse maternal outcomes across the gestational spectrum.Pregnancy Hypertens 5:198-204.

doi:10.1016/j.preghy.2015.02.002 
17. Vigil-De Gracia P, Reyes Tejada O, Calle Miñaca A, Tellez G, Chon VY, Herrarte E, Villar A, Ludmir J (2013) Expectant management of severe preeclampsia remote from term: the MEXPRE Latin Study, a randomized, multicenter clinical trial.Am J Obstet Gynecol 209:425.e1-

8. doi:10.1016/j.ajog.2013.08.016

18. Phianpiset R, Phattanachindakun B, Boriboonhirunsarn D (2017) Prevalence, Risk Factors, and Pregnancy Outcomes of Early-onset Severe Preeclampsia among Severe Preeclamptic Women in Siriraj Hospital. Thai J Obstet Gynaecol 25:26-34.

19. Abildgaard U, Heimdal K (2013) Pathogenesis of the syndrome of hemolysis, elevated liver enzymes, and low platelet count (HELLP): a review. Eur J Obstet Gynecol Reprod Biol 166:117-123.

20. Craici IM, Wagner SJ, Bailey KR, Fitz-Gibbon PD, Wood-Wentz CM, Turner ST, Hayman SR, White WM, Brost BC, Rose CH, Grande JP, Garovic VD (2013) Podocyturia predates proteinuria and clinical features of preeclampsia: longitudinal prospective study.Hypertension 61:1289-1296. doi:10.1161/HYPERTENSIONAHA.113.0111521.

21. Rosenstein MG, Cheng YW, Snowden JM, Nicholson JM, Doss AE, Caughey AB (2012) The risk of stillbirth and infant death stratified by gestational age in women with gestational diabetes. Am J Obstet Gynecol 206:309.e1-7.

22. Ganzevoort W, Rep A, de Vries JIP, Bonsel GJ, Wolf H (2006) Prediction of maternal complications and adverse infant outcome at admission for temporizing management of early-onset severe hypertensive disorders of pregnancy. Am J Obstet Gynecol 195:495-503.

23. O'Gorman N, Wright D, Rolnik DL, Nicolaides KH, Poon LC (2016) Study protocol for the randomised controlled trial: combined multimarker screening and randomized patient treatment with ASpirin for evidence-based PREeclampsia prevention (ASPRE). BMJ Open 6.

\section{Figures}


Singleton pregnant women diagnosed with early-onset preeclampsia with severe features

$$
(\mathrm{N}=392)
$$

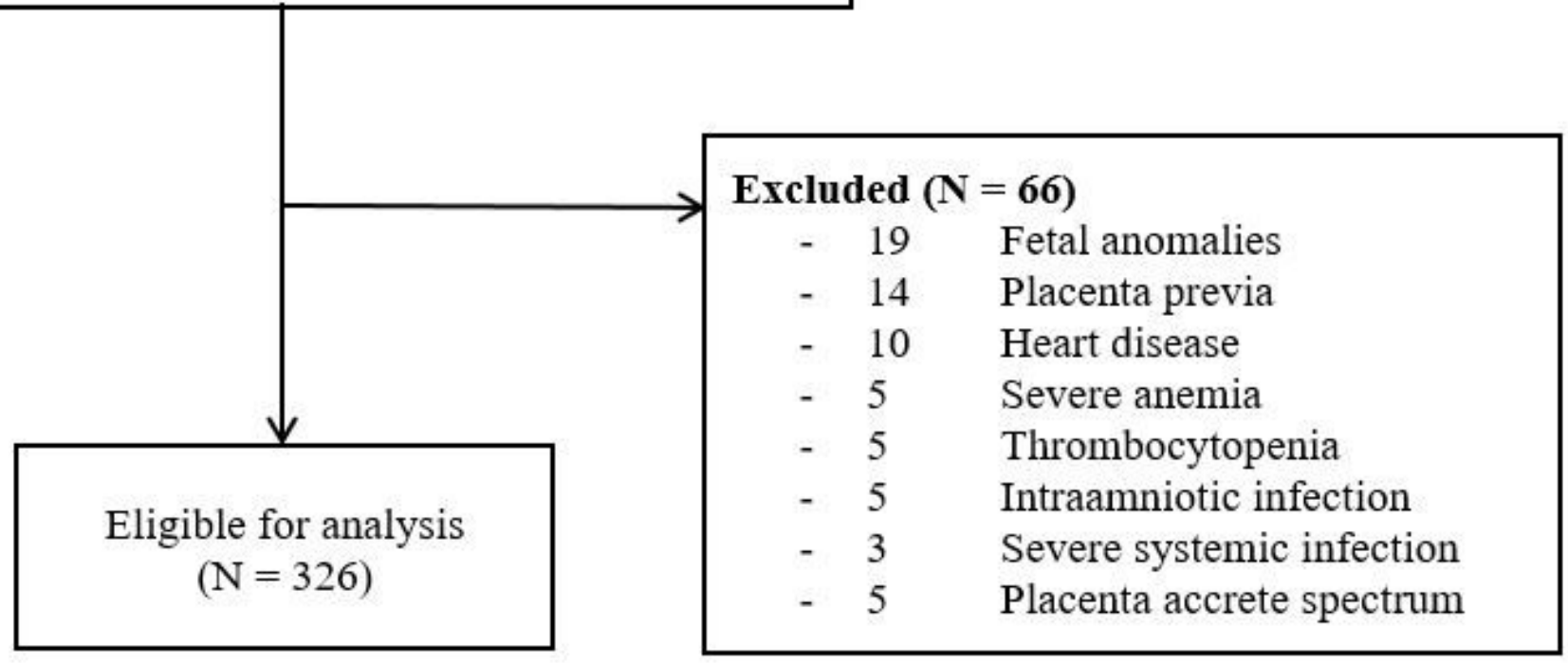

Figure 1

The study flow chart 